\title{
ENGINEERING GEOLOGICAL CONDITIONS IN THE CENTRAL AREA OF SHANGHAI
}

\section{CONDITIONS GÉOTECHNIQUES DANS LA ZONE CENTRALE DE SHANGHAÏ}

\author{
Ch. SCHROEDER*, A. DASSARGUES*, X.L. LI**
}

The engineering geological characteristics (mainly the geotechnical conditions) needed for input in the model have been determined by a compilation, as exhaustive as possible, of existing data, available in several Chinese scientific departments.

This information has been completed by in situ tests and by laboratory tests performed in Shanghai or in Belgium.

\section{Geotechnical formations}

The previous studies of the geotechnical conditions in Shanghai have led to the division of the upper seventy meters of the Quaternary overburden into six geotechnical formations, from top to bottom as follows:

\section{Superficial layer}

The upper part of this first formation is composed of browny-yellow silts. The lower part consists of mixed silty sand and silts. The superficial layer contains the phreatic aquifer.

\section{First compressible layer}

The top of this formation is between 3 and $20 \mathrm{~m}$ depth, its thickness being around 3 to $12 \mathrm{~m}$.

The upper part consists of muddy silts interlayered with silty sands. The lower part consists of muddy clay.

\section{Second compressible layer}

The top of the formation is at about 20 to $40 \mathrm{~m}$ depth, the thickness being in the range 5 to $20 \mathrm{~m}$.

The upper part consists of muddy clay, the middle one of grey silty sand mixed with silty loess.

The lower part contains grey muddy silts interstratified with silty sands, organic material and some gas.

\section{Dark Green Stiff Clay (D.G.S.C.)}

When this important horizon is present, its thickness reaches a maximum of about $8 \mathrm{~m}$. This layer of high compactness and high strength is often used as a foundation level for piles.

\section{First aquifer}

This formation consists of fine yellow sand (quartz) with some opaque constituents. The top is situated at $30-45 \mathrm{~m}$ depth, the bottom at about $35-65 \mathrm{~m}$.

\section{Third compressible layer}

This layer, whose top is situated at about $35-45 \mathrm{~m}$ depth with a thickness around $20-35 \mathrm{~m}$, is composed of muddy silts and multilayered silts and fine sands.

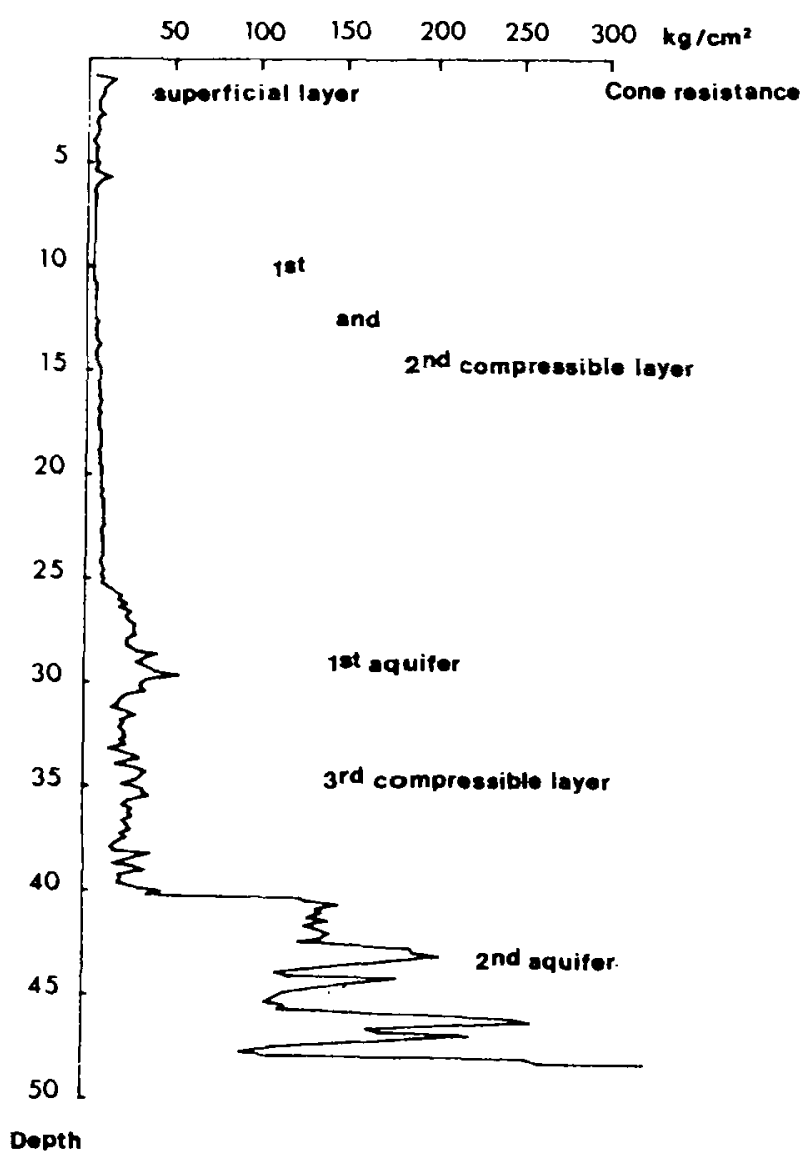

Fig. 1: A typical example of CPT results.

\footnotetext{
* Laboratoires de Géologie de l'Ingénieur. d’Hydrogéologie et de Prospection Géophysique, Úniversité de Liège, Liège, Belgique.
}

** Shanghai Station of Environmental Geology, Shanghai, P.R. China. 


\section{Second aquifer}

The second aquifer consists essentially of fine sands. Its top is situated between 65 and $80 \mathrm{~m}$ depth.

\section{In situ tests}

The in situ tests consist of some penetration tests (C.P.T.), pressuremeter tests and well logging.

\section{- Cone penetration tests}

The cone penetration tests have been performed by the Shanghai Geological Center and some additional results come from data by consultants. The main purpose of performing this kind of test was the determination of the foundation level, generally the Dark Green Stiff Clay layer (D.G.S.C.).

Figure 1 shows a typical example of CPT result (diagram of the cone resistance $\left(Q_{v}\right)$, function of the depth).

As a summary, the ranges of the $Q_{c}$ values are :

- superficial laver:

$700 \leq \mathrm{Q}_{c} \leq 2000 \mathrm{kPa}$

- first compressible laver and top of the second compressible laver:

$200 \leq Q_{c} \leq 500 \mathrm{kPa}$;

- lower second compressible layer: $450 \leq \mathrm{Q}_{\mathrm{c}} \leq 1600 \mathrm{kPa}$;
- D.G.S.C. laver.

$1500 \leq Q_{c} \leq 3500 \mathrm{kPa}$

- third compressible laver:

$2000 \leq Q_{c} \leq 5000 k P_{a}$ :

- second aquifer :

$10000 \mathrm{kPa} \leq \mathrm{Q}_{\mathrm{c}}$.

\section{- Pressuremeter tests}

Some pressuremeter tests have been carried out in collaboration with the Belgian team. As results. they give a range of the limit pressure $\left(p_{1}\right)$ from 400 to $1200 \mathrm{kPa}$ and pressuremeter modulus (Ep) from 5 to $18 \mathrm{MPa}$ $\mathrm{kg} / \mathrm{m}^{2}$ for layers between 0 and $25 \mathrm{~m}$ depth. These results permit improvement of the laboratory data. but they were too few to allow direct calculations of geotechnical parameters.

- Well-logging

The well-loggings, gamma-ray, gamma-gamma and neutron-neutron. have been performed in collaboration with the Chinese team, in eleven boreholes with $70 \mathrm{~m}$ to $150 \mathrm{~m}$ logged.

They have provided information on clay-content, density and water content which has been used in the correlations and interpretations in order to define more clearly the complex geometry of the different formations.

An example of well-logging is given on Figure 2 where it should be noted that occurence of gas in the second

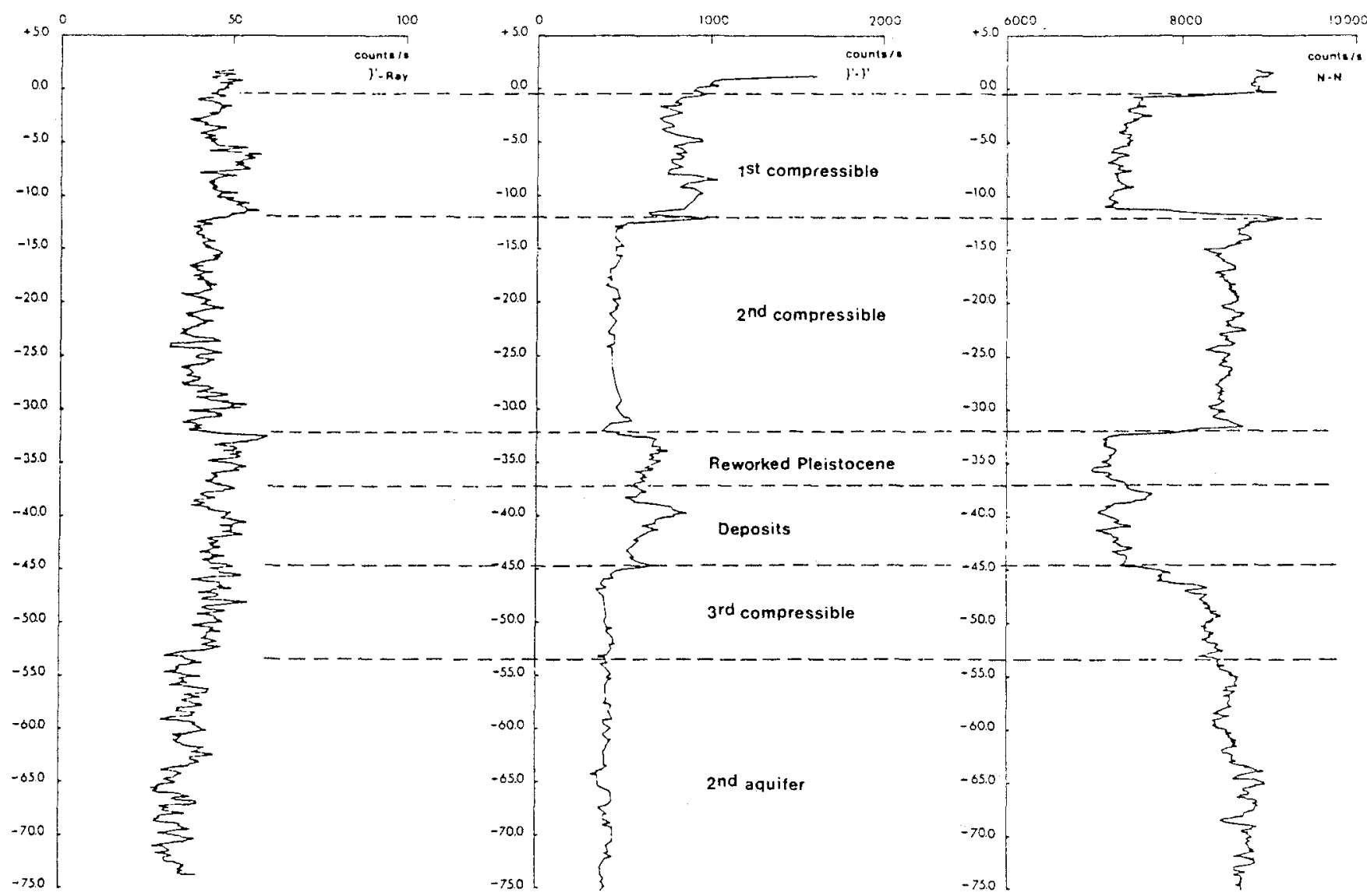

Fig. $2: \gamma$-ray, $\gamma-\gamma$ and neutron well-logging. 

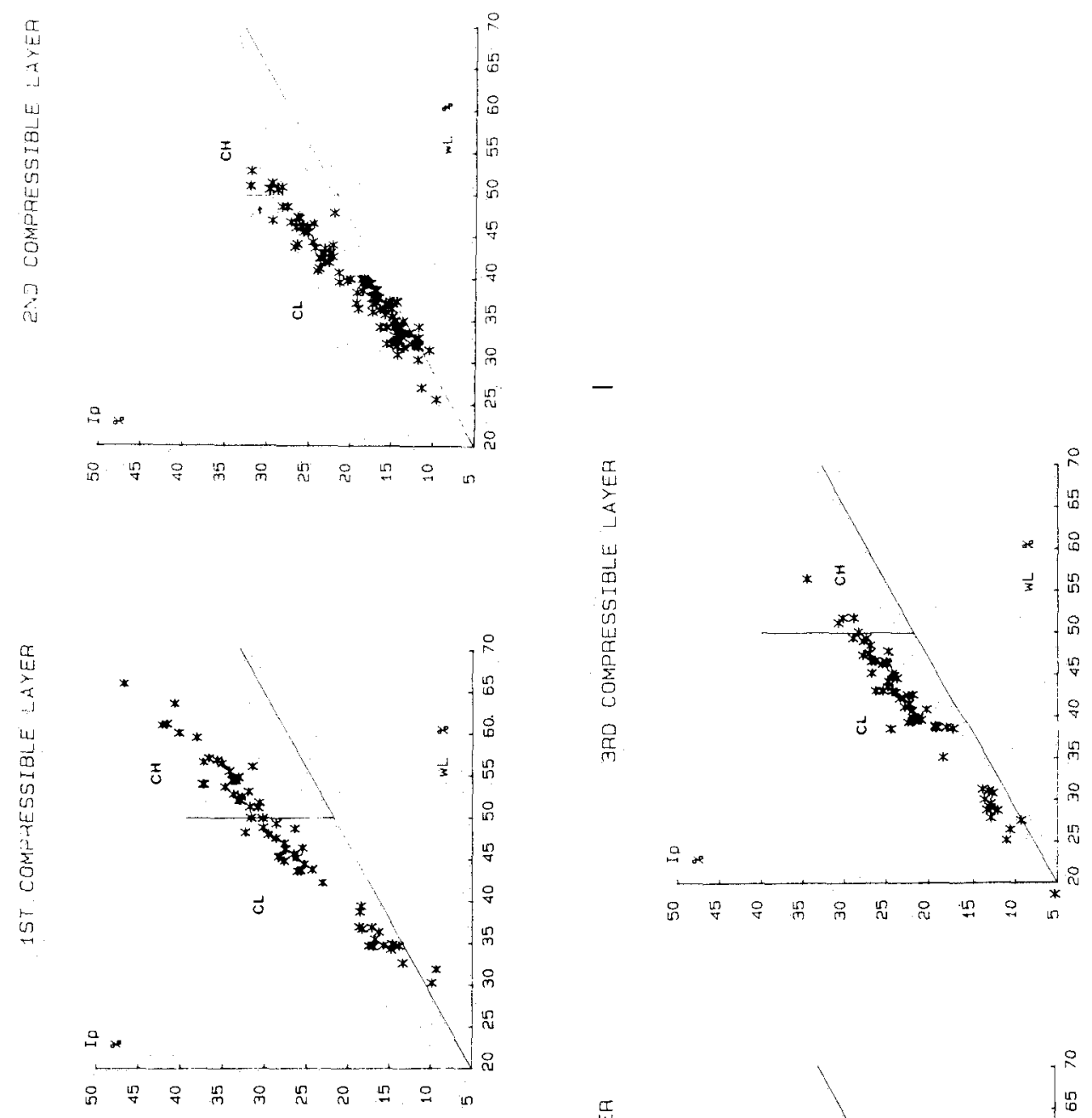

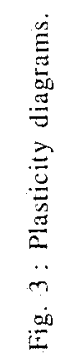
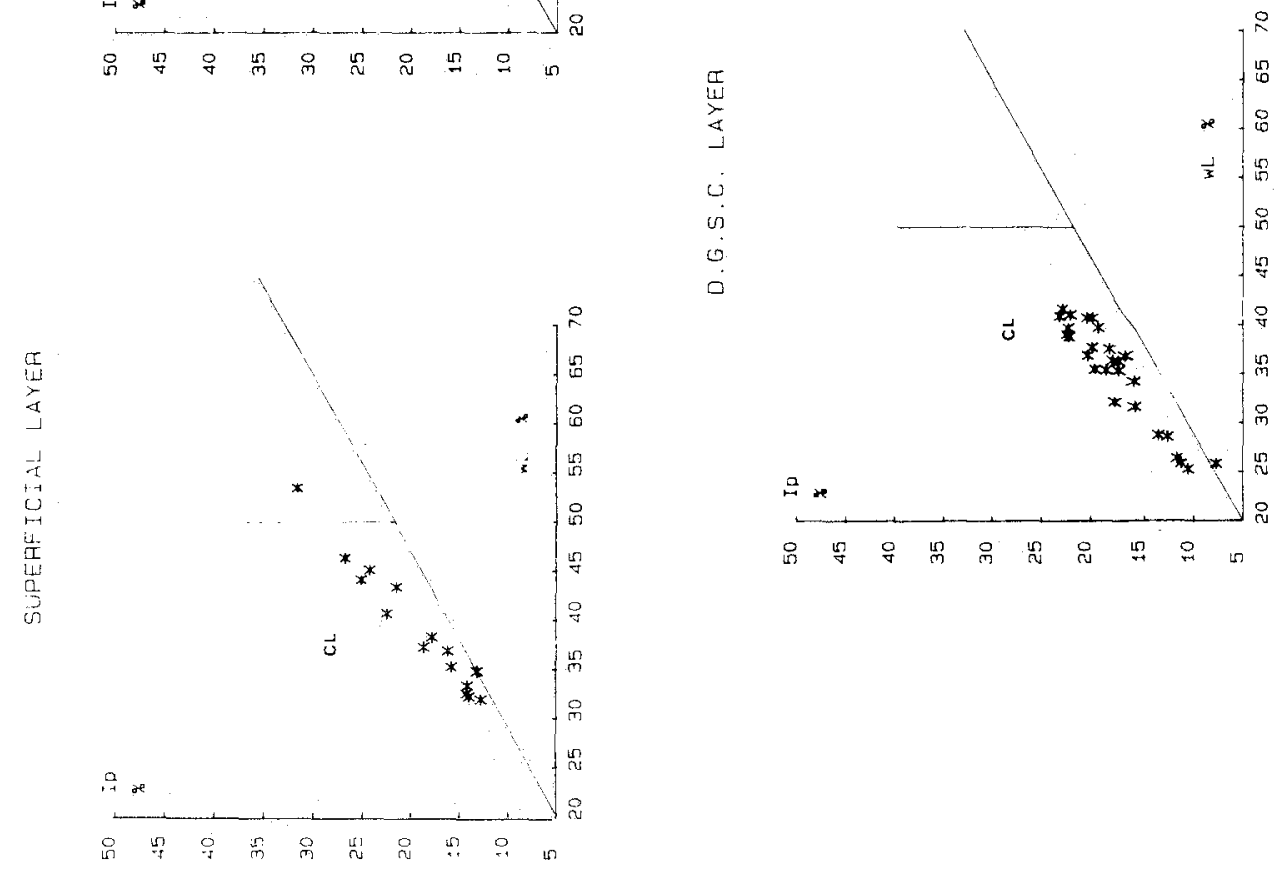

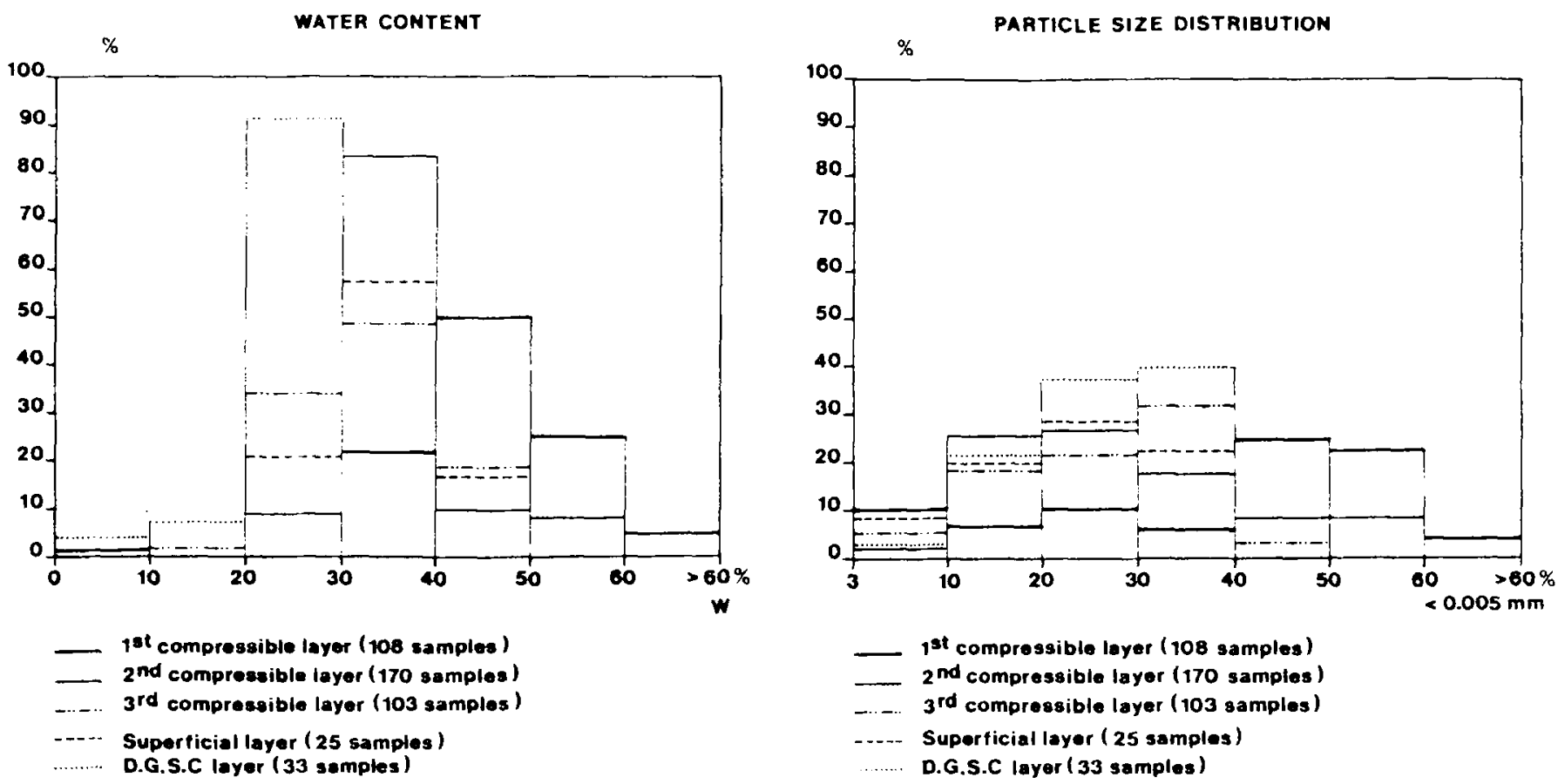

Fig. 4: Histogram of the water content.

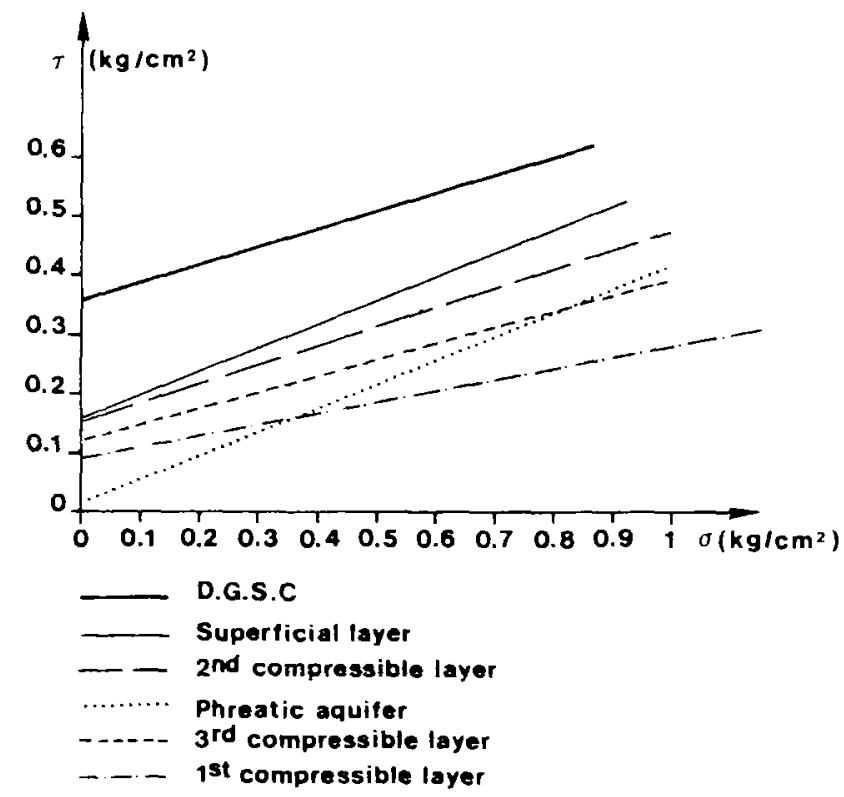

Fig. 6: The Mohr-Coulomb failure envelopes.

\section{SHEAR RESISTANCE}

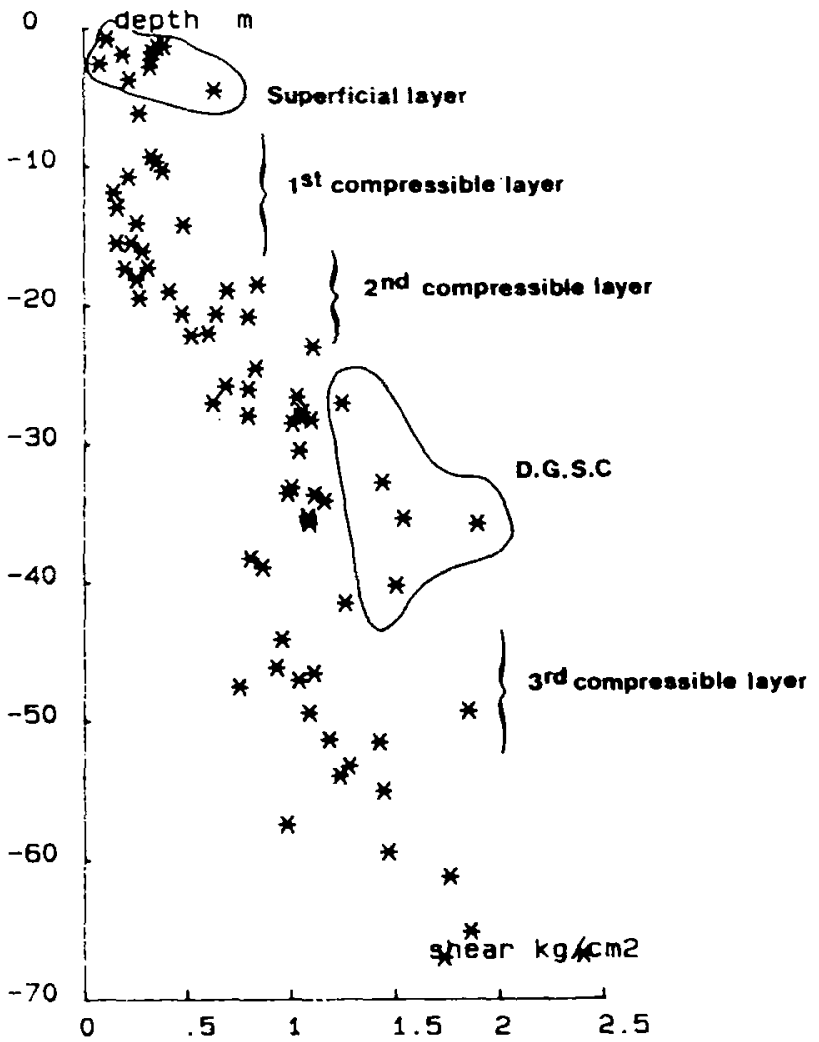

Fig. 7 : Diagram of the shear resistance versus depth. 


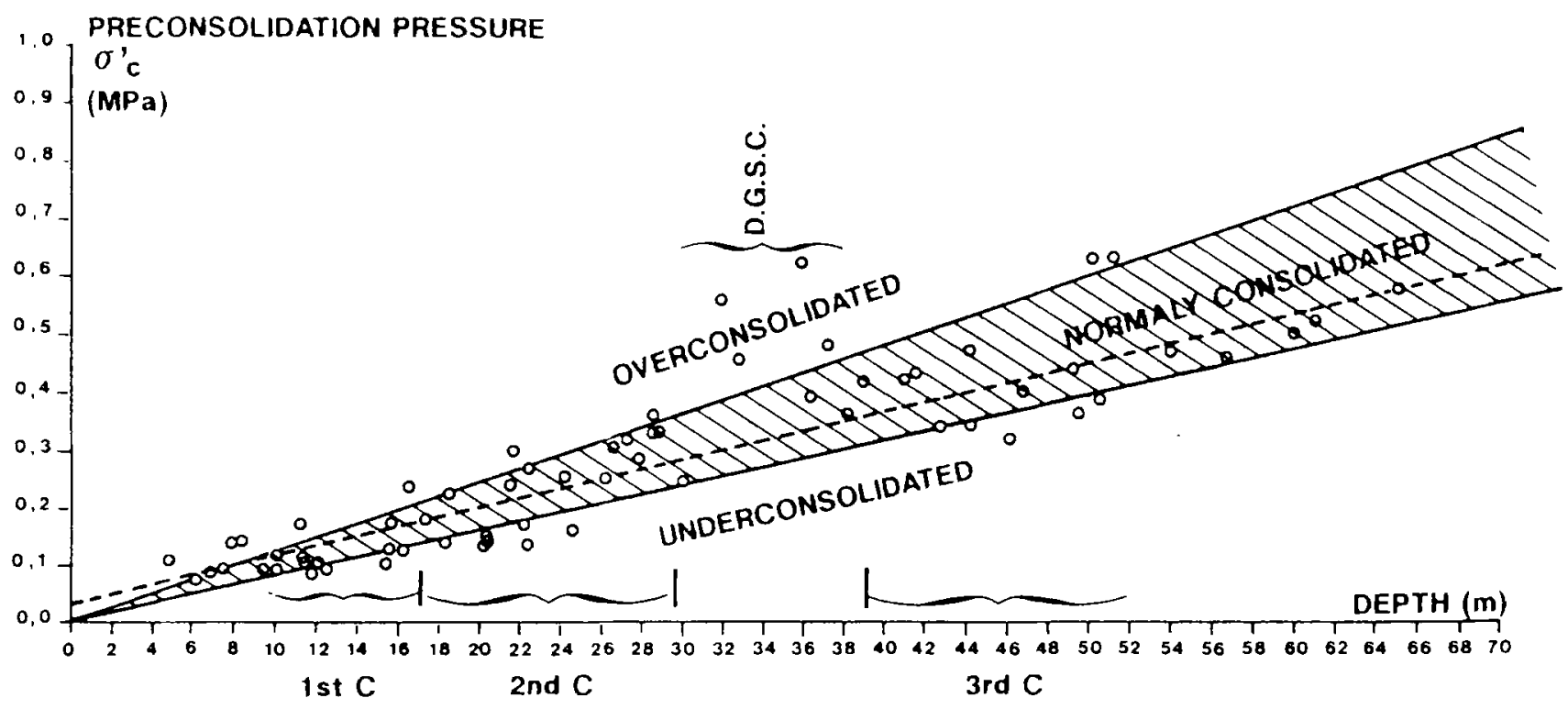

Fig. 8: Measured preconolidation pressures versus depth.

compressible laver is particularly evident in the neutron-neutron log.

\section{Laboratory tests}

About 450 laboratory tests, mainly "identification" tests have been compiled. In addition, about twenty triaxial, consolidation (oedometer) and high pressure consolidation tests have been carried out in Shanghai and in Belgium. The clay minerals have been investigated by the $X$-ray method. The results can be summarized as follows:

\section{a. Physical properties}

They are deduced from identification tests on disturbed and undisturbed samples with measurement of :

- moisture content, per cent of dry weight:

- Atterberg's limits, liquid $w_{L}$, plasticity index $I_{p}$;

- dry unit weight $\gamma_{\mathrm{d}}$;

- percentage of particle size diameter lower than $0.005 \mathrm{~mm}$ and $0.002 \mathrm{~mm}$.

From these parameters and assuming the value of the unit weight of solids $\left(\gamma_{\mathrm{s}}=2.7 \mathrm{~g} / \mathrm{cm}^{3}=25.48 \mathrm{kN} / \mathrm{m}^{3}\right)$ the following parameters are deduced:

- porosity $n=\left(\gamma_{s}-\gamma_{d}\right) / \gamma_{s}$;

- void ratio $e=\left(\gamma_{\mathrm{s}}-\gamma_{\mathrm{d}}\right) / \gamma_{\mathrm{d}}$

- submerged unit weight $\gamma=\gamma_{d}(1+w)$.

\section{1) Plasticity characteristics}

The plasticity diagrams (Fig. 3) are plotted for the different geological units distinguished by the Quaternary analysis.

According to the U.S.C.S. classification the majority of the samples may be qualified $\mathrm{CL}(\mathrm{CL}=\mathrm{Clay}$ of $\mathrm{Low}$ compressibility) but $\mathrm{CH}(\mathrm{CH}=$ Clay of High compressibility) is also distinguished in the first compressible laver.

\section{2) Particle size distribution and water content}

Histograms of the water content (Fig. 4) and of the percentage of particle size lower than $0.005 \mathrm{~mm}$ (Fig. 5). ilustrate the higher plasticity of the first compressible laver.
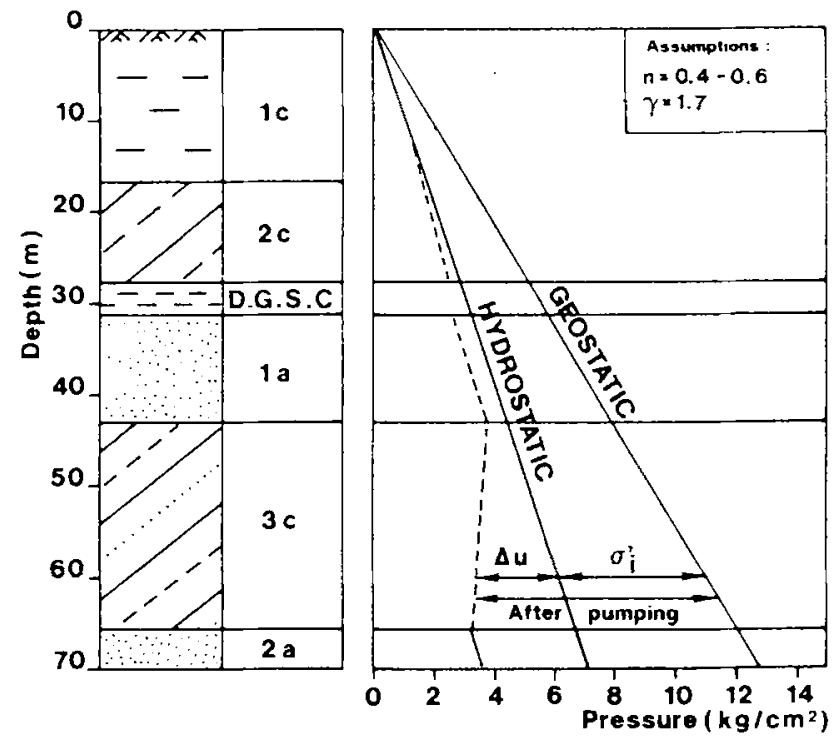

1c: $1^{\text {st }}$ compressible layer
$2 \mathrm{c}: 2^{\text {nd }}$ compressible layer
$1 \mathrm{a}: 1^{\text {st }}$ aquifer
$3 \mathrm{c}: 3^{\text {rd }}$ compressible layer
$2 \mathrm{a}: 2^{\text {nd }}$ aquifer

$\Delta u$ : Pore pressure decrease due to pumping $\sigma_{i}^{\prime}$ : Initial effective stress

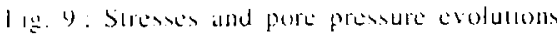


The relations between dry unit weights and moisture contents are nearly the same for each layer proving the assumed non-variability of the grains unit weight.

\section{b. Mechanical properties}

\section{1) Strength tests}

Consolidated undrained (C.U.) triaxial compression tests have been performed on undisturbed samples. The Mohr-Coulomb failure envelopes are deduced for samples taken from the different layers (Fig. 6) and the shear resistance (by simple shear tests) is plotted versus depth (Fig. 7). The results indicate that:

- the D.G.S.C. layer is stronger and possesses a cohesion and a higher shear resistance:

- the phreatic aquifer (samples were probably disturbed) has no cohesion;

- the first compressible layer (mainly between - 10 and $-20 \mathrm{~m}$ ) is less resistant.

\section{2) Compressibility}

High and low pressure oedometer tests have been performed on undisturbed samples from each clayey layer. The compression index $\mathrm{C}_{\mathfrak{c}}$, the consolidation coefficient $C_{r}$ and the permeability $K$ have been calculated for each loading step. The ranges of $C_{i}$ values for the different layers are obtained:

- phreatic aquifer

$$
\begin{aligned}
& 0.04 \leq \mathrm{C}_{\mathrm{c}} \leq 0.09 \\
& 0.4 \leq \mathrm{C}_{\mathrm{c}} \leq 1.2 \\
& 0.3 \leq \mathrm{C}_{\mathrm{c}} \leq 1.2 \\
& 0.2 \leq \mathrm{C}_{\mathrm{c}} \leq 0.4 \\
& 0.2 \leq \mathrm{C}_{\mathrm{c}} \leq 0.3 \\
& 0.3 \leq \mathrm{C}_{\mathrm{c}} \leq 0.5 \\
& 0.15 \leq \mathrm{C}_{\mathrm{c}} \leq 0.2
\end{aligned}
$$

- second aquifer The preconsolidation stress has been determined and
compared to the actual in situ stress. assuming a bulk density of 1.8 and $2.2 \mathrm{~g} / \mathrm{cm}^{3}$. The first and second compressible lavers are normally consolidated. the third compressible laver is slightly overconsolidated and the D.G.S.C. is obviously overconsolidated. The slight overconsolidation of the third compressible laver may have been induced by the consolidation due to the important pumpings before 1965 .

About 60 values of the preconsolidation stress are drawn as function of the depth on Figure 8. The linear correlation is

$$
\sigma_{i}{ }_{i}=0.31+0.084 \mathrm{~h}(\mathrm{~h}=\text { depth })
$$

with a correlation coefficient $=0.94$

For the computation of the settlements, the knowledge of the initial void index, $e_{i n i t}$ is needed (Dassargues et al., 1989). Now, all the oedometer tests have been carried out during the last 20 years so that no test has been run on "intact" samples. The tested soils have been already consolidated because of the pumpings.

The evolution of the effective stresses from 1920 up to the date of the test is known according to the Ter-
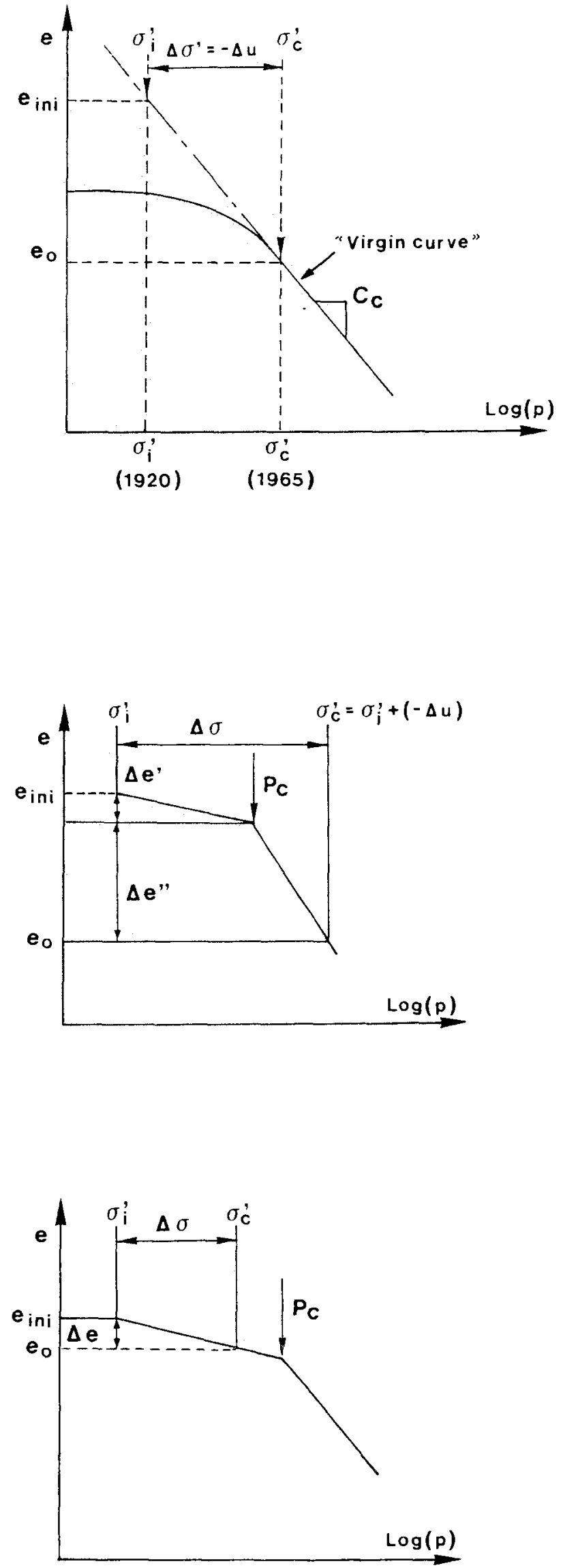

HE. 10: Determinalion of ea. Normally consoliditted soils. 
arghi's principle $\left(\Delta \sigma^{\prime}=-\Delta\right.$ p. variation of the pressure produced by the pumping. see Figure 9).

The initial void ratio. in 1920), has been calculated from the results of the present tests (Dassargues et al. 1989). For the calculation of $e_{\text {init }}=c_{n}+\Delta c, 2$ cases could occur : -- normally consolidated soils (Fig. 10) as Ist. 2nd. 3 ad compressible lavers and 1 st and 2 nd aluifer:

$$
\Delta \mathrm{e}=\mathrm{C}_{\mathrm{C}} \cdot \log \left[\left(\sigma_{\mathrm{i}}^{\prime}+\Delta \sigma^{\prime}\right) / \sigma_{\mathrm{i}}\right]
$$

-- overconsolidated soils: D.G.S.C. layer: Two calses:

- the ground has only an elastic rebound if

$\Delta \sigma^{\prime}=-\Delta \mathrm{u} \leq\left(\partial^{\prime} \mathrm{p}-\sigma_{\mathrm{i}}^{\prime}\right.$ and $\Delta \mathrm{e}$ is very small (Fig. 11).

- $\Delta \sigma^{\prime}=-\Delta \mathrm{u}>\left(\sigma_{p}^{\prime}-\sigma_{1}^{\prime}\right)$ and (Fig. 12)

$$
\begin{aligned}
\Delta \mathrm{e} & =\Delta_{\mathrm{c}}^{\prime}+\Delta_{\mathrm{c}}^{\prime \prime} \\
& =C_{\mathrm{c}} \log \left(\sigma_{\Gamma}^{\prime} / \sigma_{i}^{\prime}\right)+C_{\mathrm{c}} \log \left[\left(\sigma_{\mathrm{i}}^{\prime}+\Delta_{\sigma}^{\prime}\right) / \sigma_{\mathrm{p}}^{\prime}\right] .
\end{aligned}
$$

\section{c. X-ray analyses}

Detailed qualitative and quantitative analysis by $\mathrm{X}$-ray diffraction have been performed on more than 50 samples by the Laboratory of Clay Minerals Geology of the Liniersity of Liege (Prof. J. Theres). The results have shown that illite and kalolinite are the dominant clay components. Beside them. the complex clay association is such that no clear cut or evolution can be traced. The trends in occurrences of water acceptors and swelling components have been determined. These properties are to be linked to the compressibility of the sediment under drained consolidation.

\section{Conclusion}

The geotechnical data gathered by the compilation of existing data and improved by in situ and laboratory tests provide the characteristics of the seven typical layers of the upper $70 \mathrm{~m}$ of the Shanghai sub surface.

The average values and the range of the main parameters are synthetized in Table 1.

\section{Reference}

DASSARGLES A. SCHROEDER C. and MONJOIE A., 1989: The hydrogeology and enginecring geology of the Shanghai areal. L.G.I.H.. RLport SPPS/R91. Linpublished.

rible 1: Summary of gentechaicial properties.

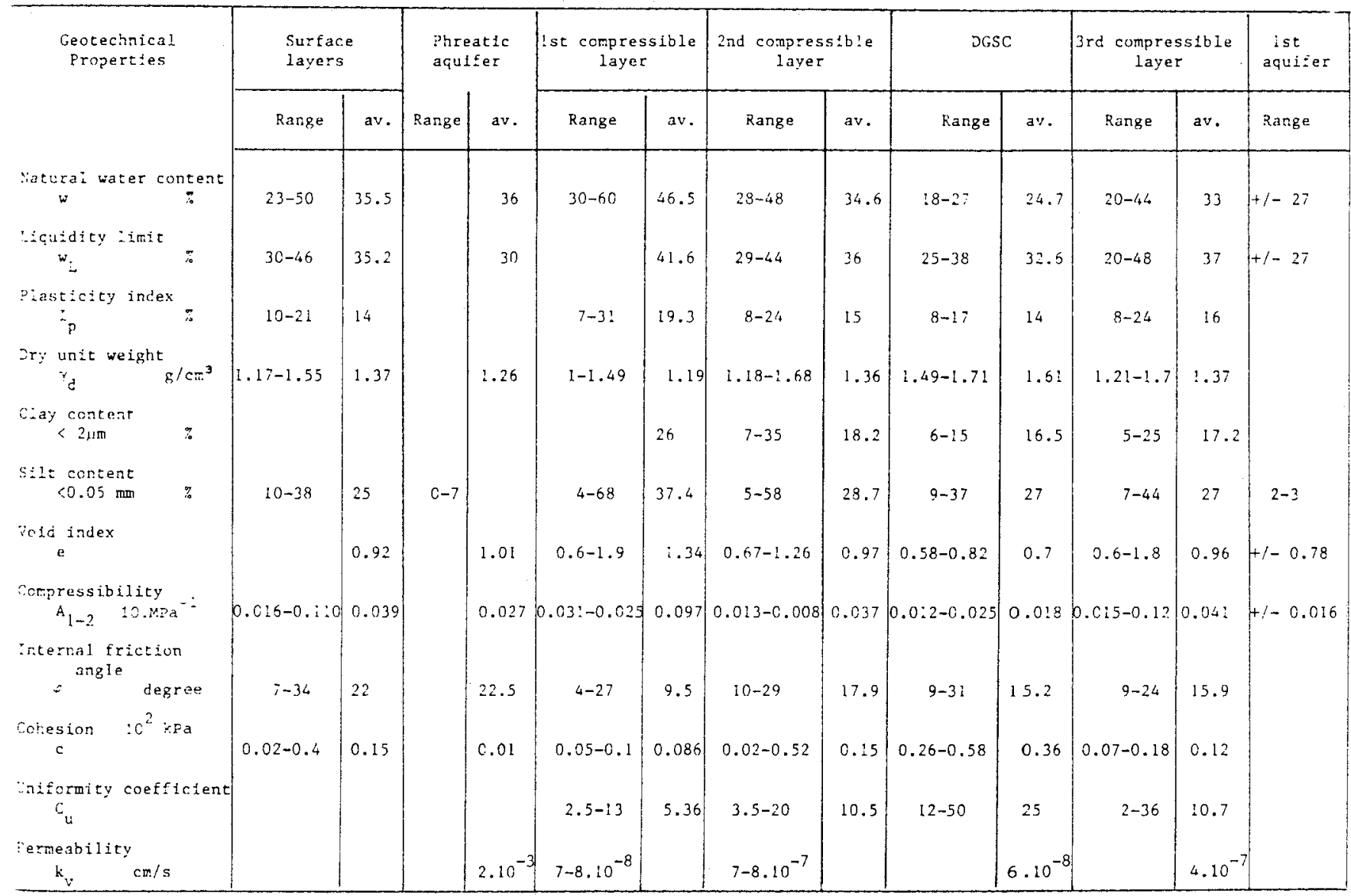

